\title{
Infectious Causes of Cholesteatoma and Treatment of Infected Ossicles prior to Reimplantation by Hydrostatic High-Pressure Inactivation
}

\author{
Wycliffe Omurwa Masanta, ${ }^{1}$ Rebecca Hinz, ${ }^{2}$ and Andreas Erich Zautner ${ }^{1}$ \\ ${ }^{1}$ Institut für Medizinische Mikrobiologie, Universitätsmedizin Göttingen, 37075 Göttingen, Germany \\ ${ }^{2}$ Fachbereich Tropenmedizin am Bernhard-Nocht-Institut, Bundeswehrkrankenhaus Hamburg, 20359 Hamburg, Germany \\ Correspondence should be addressed to Andreas Erich Zautner; azautne@gwdg.de
}

Received 29 December 2014; Accepted 20 January 2015

Academic Editor: Chin-Lung Kuo

Copyright (C) 2015 Wycliffe Omurwa Masanta et al. This is an open access article distributed under the Creative Commons Attribution License, which permits unrestricted use, distribution, and reproduction in any medium, provided the original work is properly cited.

\begin{abstract}
Chronic inflammation, which is caused by recurrent infections, is one of the factors contributing to the pathogenesis of cholesteatoma. If reimplantation of autologous ossicles after a surgical intervention is intended, inactivation of planktonic bacteria and biofilms is desirable. High hydrostatic pressure treatment is a procedure, which has been used to inactivate cholesteatoma cells on ossicles. Here we discuss the potential inactivating effect of high hydrostatic pressure on microbial pathogens including biofilms. Recent experimental data suggest an incomplete inactivation at a pressure level, which is tolerable for the bone substance of ossicles and results at least in a considerable reduction of pathogen load. Further studies are necessary to access how far this quantitative reduction of pathogens is sufficient to prevent ongoing chronic infections, for example, due to forming of biofilms.
\end{abstract}

\section{Introduction}

Cholesteatoma is a noncancerous condition that is characterized by abnormal growth of squamous epithelial cells in the middle ear and mastoid destroying the ossicles resulting in loss of hearing. This condition affects children more aggressively than adults. There are two types of cholesteatoma, namely, congenital and acquired cholesteatoma. General symptoms include release of smelly fluid from infected ear, loss of hearing, and pain on the infected ear [1]. Treatment is a combination of surgery and the administration of antimicrobials $[2,3]$. However, sometimes recovery is complicated by postsurgery infections [4].

The etiology of cholesteatoma is not yet completely understood, but various studies have revealed that a number of factors cooperate in a synergistic way to cause the forming of this nonneoplastic keratinizing lesion, which is characterized by enhanced proliferation of epithelial cells with aberrant morphologic characteristics [1,5-7]. These factors include persistent microbial infection resulting in chronic inflammation, consecutive invasion by cells of the immune system, Eustachian tube dysfunction, aggregation of cellular debris, and increased viscosity of middle ear effusions, ingrowth of blood vessels, auditory ossicle resorption, and epithelial hyperplasia $[7,8]$.

During surgical treatment of cholesteatoma, affected parts of the ossicular chain must be removed. Because of best recovery of hearing autologous retransplantation of ossicles is still the therapy of choice [9, 10]. Therefore, devitalization of cholesteatoma-affected parts of the ossicular chain and their reimplantation would be beneficial. The hydrostatic high-pressure technology (HHD) is a promising method that can remove the cellular components during ongoing surgery. In the food industry, high pressure is already used as a substitute for pasteurization. Microorganisms are inactivated by high-pressure, but the required pressure level depends on the respective germ $[11,12]$. The mechanism of action of hydrostatic high-pressure is essentially based on 
the changes taking place at the phase boundary of water to other molecules, in particular, the epithelial or bacterial cell surface. Under increasing pressure water molecules penetrate into the cavities of complex macromolecules and blow up the quaternary and tertiary structure of complex macromolecules. Covalent bonds are unaffected since the primary structure is not changed by high-hydrostatic pressure $[13,14]$.

This paper will give a detailed overview on persistent microbial infections associated with cholesteatoma and their elimination by hydrostatic high pressure (HHP) during surgery to minimize the possibility of postsurgery infection.

\section{Persistence of Microbial Pathogens in spite of Surgical Therapy of Cholesteatoma}

Colonization by bacteria leads to biofilm formation on the ossicles of the middle ear. These biofilms lead to impaired clearance and consecutive chronic middle ear infection, which triggers chronic inflammation. Mediators expressed during inflammation like IL-1, PAF, and TNF-alpha induce mucin hypersecretion, hyperproliferation of epithelial cells and keratinocytes and bone resorption by activation of collagenases and osteoclasts [7].

Quite a number of Gram-positive, Gram-negative, and fungal pathogens have been isolated from cholesteatoma tissues (please see Table 1) [15-23]. Biofilm formation is believed to play an important role in persistence of these pathogens in the middle ear hence maintaining chronic inflammation eventually leading to the establishment of cholesteatoma $[17,18]$. A recent in vitro study revealed that biofilm was responsible for the persistence of more than $50 \%$ of isolates of microbial pathogens in ossicles that were obtained from a cholesteatoma tissue [23]. The great variety of suspected relevant pathogens suggests that the general inflammatory stimulus due to bacterial infections seems to be more important than the causing bacterial species itself. Further, as the bacterial flora of the upper respiratory tract physiologically colonizes the middle ear cavity, it is difficult to discriminate relevant pathogens from harmless colonizers.

As we stated in the introduction, treatment of cholesteatoma is usually based on surgery [2, 3, 24-28], including the surgical removal of chronically inflamed ossicles. Relapses are frequent with recurrence rates $<10 \%$ already being considered as therapeutic success [4, 29-31]. Incomplete removal of pathogens or their biofilms, in particular, is a proven risk factor for recurrence [31].

For the treatment of middle ear cholesteatoma, reimplantation of autologous ossicles is frequently applied [9, 10, 32] because optimal recovery of hearing is hardly achieved by allogeneic implants despite good biocompatibility and stability. The implantation of fixated homologue ossicles from an "ossicle bank" bears the potential risk of slow-virus or prion transmission and is, therefore, critically discussed [33].

Cholesteatoma cells on autologous ossicles should be thoroughly inactivated prior to any reimplantation approaches. The surgeon should abstain from immediate reimplantation if a readily removable coat of cholesteatoma
TABLE 1: Bacterial and fungal species isolated from cholesteatoma material according to [9-17].

\begin{tabular}{|c|c|}
\hline Subgroup & Species \\
\hline \multirow{11}{*}{$\begin{array}{l}\text { Gram-positive } \\
\text { aerobic cocci }\end{array}$} & Kocuria rosea \\
\hline & Leuconostoc mesenteroides ssp. cremoris \\
\hline & Micrococcus luteus \\
\hline & Staphylococcus aureus \\
\hline & Staphylococcus auricularis \\
\hline & Staphylococcus capitis \\
\hline & Staphylococcus epidermidis \\
\hline & Staphylococcus hominis \\
\hline & Staphylococcus simulans \\
\hline & Streptococcus mitis \\
\hline & Streptococcus sanguinis \\
\hline \multirow{3}{*}{$\begin{array}{l}\text { Gram-positive } \\
\text { aerobic rods }\end{array}$} & Bacillus licheniformis \\
\hline & Corynebacterium pseudodiphtheriticum \\
\hline & Turicella otitidis \\
\hline $\begin{array}{l}\text { Gram-positive } \\
\text { anaerobic cocci }\end{array}$ & Peptostreptococcus spp. \\
\hline \multirow{5}{*}{$\begin{array}{l}\text { Gram-positive } \\
\text { anaerobic rods }\end{array}$} & Clostridium bifermentans \\
\hline & Eubacterium limosum \\
\hline & Fusobacterium spp. \\
\hline & Propionibacterium acnes \\
\hline & Propionibacterium granulosum \\
\hline \multirow{2}{*}{$\begin{array}{l}\text { Gram-negative } \\
\text { aerobic cocci }\end{array}$} & Neisseria sicca \\
\hline & Neisseria subflava \\
\hline \multirow{9}{*}{$\begin{array}{l}\text { Gram-negative } \\
\text { aerobic rods }\end{array}$} & Aeromonas salmonicida \\
\hline & Acinetobacter baumannii \\
\hline & Burkholderia cenocepacia \\
\hline & Brevundimonas diminuta \\
\hline & Histophilus somni \\
\hline & Pseudomonas aeruginosa \\
\hline & Pseudomonas fluorescence \\
\hline & Ralstonia pickettii \\
\hline & Sphingomonas paucimobilis \\
\hline $\begin{array}{l}\text { Gram-negative } \\
\text { anaerobic cocci }\end{array}$ & Veillonella parvula \\
\hline \multirow{3}{*}{$\begin{array}{l}\text { Gram-negative } \\
\text { anaerobic rods }\end{array}$} & Bacteroides ureolyticus \\
\hline & Porphyromonas spp. \\
\hline & Prevotella spp. \\
\hline Yeasts & Candida albicans \\
\hline
\end{tabular}

cells or an infiltration by cholesteatoma-matrix into the bone is observed during surgery $[34,35]$.

Next to cholesteatoma cells and difficult to identify, microbial biofilms that have contributed to chronic inflammation finally leading to cholesteatoma formation may persist on explanted ossicles as well [23]. 


\section{Hydrostatic High-Pressure (HHP) to Devitalize Human Cells on Explanted Ossicles}

Hydrostatic high-pressure technology (HHP), which can effectively disturb or even completely destroy eukaryotic cell membranes, elements of the cytoskeleton, and enzyme systems [36-38], allows for the inactivation of cholesteatoma cells on the ossicles. Previous studies have demonstrated successful devitalizing of bone tissue with intact bone matrix by HHP [39, 40]. Bone and tendon materials [41, 42] are resistant to pressure up to $600 \mathrm{MPa}$ without measurable alteration of their biomechanical properties. HHP efficiently destroys vital human cells without affecting rigid structures of bone tissue $[13,14,43]$. For explanted ossicles, a thorough eradication of vital cholesteatoma cells by pressure of $400 \mathrm{MPa}$ has previously been demonstrated. The cellular damage was mainly caused by extensive membrane disruption [44]. Accordingly, HHP allows the surgeon to destroy any harmful vital human cellular components of ossicle interponates within the surgical procedure.

Infectious complications and persistence of inflammation-inducing biofilms are, however, other risks of reimplantation of ossicles during cholesteatoma surgery. Inactivation of respective microorganisms is, therefore, another point of concern.

\section{Hydrostatic High-Pressure (HHP) to Devitalize Microbial Pathogens}

Several studies analyzed the inactivation of microorganisms by HHP application comprising both bacteria $[11,12,45]$ and viruses [46] in food samples. By doing so, the procedure can replace pasteurization which is commonly applied in food industry. The target species defines the required pressure, which is necessary for a thorough inactivation within the sample $[11,12]$. In contrast, data on the effects of HHP on colonizing or infecting pathogens in human samples are still rather scarce.

In a recently published study, a moderate inactivating effect of HHP of $350 \mathrm{MPa}$ about 10 minutes, which had been shown to eradicate cholesteatoma cell growth on explanted human ossicles without harming the ossicle itself [44], was shown for colonizing microbes (scheme of experimental setup in Figure 1) [23]. In this study, those HHP conditions allowed for a complete inactivation of bacteria in about half of the tested clinical samples and a thorough eradication of vital cholesteatoma cells. The result was not unexpected as different bacterial species show varying susceptibilities to HHP $[12,47]$. Furthermore, nonhomogenously inactivating effects have been observed even within defined species, namely, Corynebacterium pseudodiphtheriticum, Propionibacterium acnes, Staphylococcus aureus, Staphylococcus hominis, Staphylococcus simulans, Staphylococcus caprae, and Turicella otidis. For these bacterial species $350 \mathrm{MPa}$ for 10 minutes are close to the their inactivation threshold, therefor semi-quantification of bacterial load after pressure treatment yields equal or

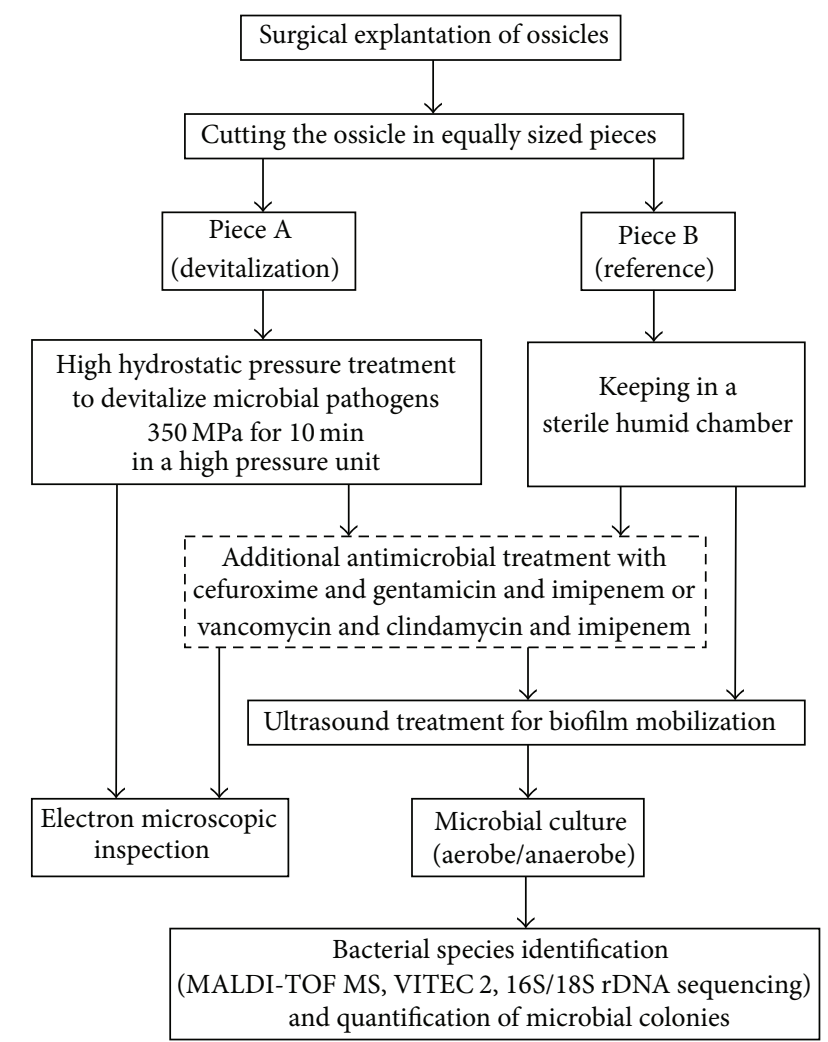

FIGURE 1: Flow chart of the experimental setup for high hydrostatic pressure treatment on human ossicles. After surgical explanation of human ossicles the bones were cut into two equally sized pieces but in case of additionally antibiotic treatment the bones were cut into six equally sized pieces. Piece(s) A was/were HHP-treated at $350 \mathrm{MPa}$ for $10 \mathrm{~min}$, while Piece(s) B was/were kept in a sterile humid chamber. Optionally, the pieces were treated with either cefuroxime $11.1 \mathrm{mg} / \mathrm{mL}$, gentamicin $44.4 \mathrm{mg} / \mathrm{mL}$, and imipenem $3.7 \mathrm{mg} / \mathrm{mL}$ or vancomycin $11.1 \mathrm{mg} / \mathrm{mL}$, clindamycin $0.75 \mathrm{mg} / \mathrm{mL}$, and imipenem $3.7 \mathrm{mg} / \mathrm{mL}$. After treatment, microbial colonization was assessed by electron microscopy and microbial culture. Prior microbial culture bacterial biofilms were mobilized by ultrasound treatment. Microbial species identification was performed using MALDI-TOF MS (Bruker Daltonics, Bremen, Germany), VITEC 2 identification (bioMérieux, Nürtingen, Germany), and 16S/18S rDNA sequencing. For in-depth reading, see [23, 44].

even higher amount compared to untreated specimen [23]. Marked differences upon susceptibility against HHP within a species have been described so far $[48,49]$ with varying numbers of resistant subpopulations within a given strain [50]. As expected due to the protective effects of the thicker cell wall, Gram-positive strains demonstrate a higher HHP resistance than Gram-negative ones [23]. But there are differences within the Gram-negative bacteria as well. While $P$. aeruginosa is readily inactivated by HHP treatment as shown in various prior studies $[23,51]$, the nonfermenting Gramnegative, rod-shaped Acinetobacter spp. resist in a similarly efficient way as staphylococci [23]. 


\section{Known Effects of High Hydrostatic Pressure on Microorganisms}

Few of the obviously complex mechanisms of bacterial adaption to pressure are analyzed on molecular level, usually for model organisms like lactic acid bacteria. Mesophile bacteria like lactic acid bacteria can be inactivated at $200-600 \mathrm{MPa}$ about 5-60 minutes. If pressure between 200 and $300 \mathrm{MPa}$ is applied, the sigmoid killing curves usually lead to plateaus indicating resistant fractions within the populations [50]. However, adaptive strategies may vary between individual species. Genetic variability was shown to be a factor affecting HHP susceptibility [52]. The pathways of stress response to high pressure are a partial composition of stress response reactions to other stress qualities [53] and show measurable effects on expression or hydratization levels of molecules. High pressure especially alters many macromolecules while small molecules usually remain unchanged. Especially the cellular membrane is altered by the thermodynamic effects of high pressure including decreases of fluidity and integrity as well as changes of secondary and tertiary structure of membrane proteins. Thus deep-sea bacteria like Photobacterium profundum require alternative flagellar and porin system for their existence under high-pressure conditions [54]. But also macromolecular associations, that are necessary for cellular division, dissociate under high-pressure conditions due to changes in hydratization [50]. Translation and transcription are affected as well leading to the production of dysfunctional proteins within the cell [55]. In addition, HHP efficiency could be affected by factors such as microbial growth phase, prior exposure to sublethal stress conditions, as well as environment composition and conditions [23].

\section{Resistance of Bacterial Pathogens against High Hydrostatic Pressure}

Bacteria are able to recover in spite of drastically decreased viability due to HHP under favourable conditions [49, 5660]. It is further known that prior exposure towards sublethal stresses may dramatically increase resistance against HHP even in stress-sensitive microorganisms like Campylobacter jejuni [45, 61-63]. HHP-resistant variants of Listeria monocytogenes were described to be 10 to 600,000 times more resistant than the wild-type when exposed to $350 \mathrm{MPa}$ [48]. The population diversity of stress resistant Listeria monocytogenes variants suggests a high degree of genetic flexibility [52]. Previously observed lacking inactivation of $P$. aeruginosa and $S$. epidermidis in higher concentrations (about MacFarland 0.5 ) [23] is not surprising, for pressures about $900 \mathrm{MPa}$ about 5 minutes are required for a 8-9 decadic log units reduction as demonstrated for Staphylococcus, Listeria, and Salmonella [60]. Various conditions affect the inactivating effect of HHP treatment, including medium composition, $\mathrm{pH}$ value, temperature, ion concentrations (especially magnesium and calcium), sucrose concentration within the medium, growth phase of the microorganisms, and number of compression cycles $[45,49,56-62]$. The analyses of all these interfering factors will require more and larger studies if adequate models for ossicle tissue are available [23].

\section{Experience of Other Medical Disciples regarding High Hydrostatic Pressure Application for the Inactivation of Microbes on Biological Material}

Allogeneic bone transplantation comprises a risk of infection [64]. Previously described experiments with high hydrostatic pressure application about $600 \mathrm{MPa}$ to human bone samples led to a complete disinfection in no more than 2 of 37 bone samples from patients with chronic osteomyelitis [51]. Even in artificially infected bone specimens complete disinfection was achieved in no more than $66 \%$ for Staphylococcus aureus, $60 \%$ for P. aeruginosa, and $0 \%$ for Enterococcus faecium. Interestingly, blood and adherence to metal implants did not significantly alter the inactivating effect of HHP treatment, so quantitative reductions of vital bacteria about 5 decadic $\log$ units were achieved for $S$. aureus and $P$. aeruginosa. Nevertheless, the baroprotective effect on osteoarthritic bone was nonhomogeneous. Microorganisms on individual bone samples showed resistance against treatment resulting in unaltered bacterial growth [51]. In a further study, destruction of cell-wall integrity of Gram-negative strains was observed by electron microscopy, but only $71 \%$ of bone biopsies from patients with chronic bone infections were culture-negative after high hydrostatic pressure up to $600 \mathrm{MPa}$ compared with $38 \%$ negative samples without any treatment [64].

\section{Combined Effects of High Hydrostatic Pressure and Antibiotic Drugs on the Inactivation of Bacteria}

An increase in the inactivating effect of HHP on bacterial organisms in combination with different antibiotic mixtures could be confirmed for ossicle material [23]. In the respective study, the addition of antibiotics suppressed bacterial growth in culture media as might have been expected. The used antibiotic combinations in combination with HHP led to convincingly better inactivating effects than HHP alone.

Nevertheless, there is most certainly no combination of antibiotic agents that could guarantee antimicrobial effects on each possible bacterial species that could colonize the clinical material. In the mentioned study [23], the combination of vancomycin, clindamycin, and imipenem failed to inactivate a Leuconostoc mesenteroides ssp. cremoris isolate due to its intrinsic resistance to vancomycin [65]. However, considering the fact that this isolate grew no earlier than after 7 days in an enrichment broth after HHP treatment combined with antibiotics while there was no growth from the same ossicle after HHP treatment alone (personal communication with the authors of [23]), a secondary contamination cannot completely be excluded as well.

However, such laboratory results are difficult to interpret. Transport time from the pressure device to the microbiological laboratory that would be absent in case of an immediate reimplantation after pressure treatment might have an effect due to a prolonged exposure time to the antibiotic drugs. During transport, antibiotic substances can act much longer 
than the pressure itself. Further, exposure to subletal pressure is known to alter susceptibility to antibiotics, especially to substances acting at the ribosomal subunits [50].

\section{Effects of High Hydrostatic Pressure on Biofilms}

The efficiency of HHP treatment on bacterial pathogens is known to be affected by biofilm formation [52]. Biofilm growth in per se nonsterile compartments like the middle ear cavity has to be expected. Both ossicles and ossicular prostheses can harbour biofilms formed by typical colonizing bacteria of the middle ear cavity in chronically infected or colonized patients [66-68]. Respective in vivo experiments are difficult to design, because in vivo ability of biofilm formation is only poorly reproducible in vitro on a cover-slide. So in vitro growth in biofilms does not per se guarantee biofilm formation in vivo as well. In a recent study on biofilm-forming isolates from human ossicles, indeed biofilms were less susceptible to HHP treatment than planktonic bacteria as could have been suspected. At least doubling of pressure settings was necessary to eradicate similar bacterial cell quantities in biofilms as in the planktonic state for both Gram-positive and Gram-negative bacteria [23]. Interestingly, the biofilm formed by the Gram-negative pathogen was more HHPresistant than the biofilm of the Gram-positive bacterium, thus neglecting the importance of cell wall thickness in the biofilm state.

One might speculate whether an ultrasound treatment of ossicles prior to HHP treatment might strengthen the inactivating pressure effects. To the authors' knowledge, no respective studies are currently available. However, the practicability of a multistep-procedure including an ultrasound pretreatment in the clinical setting during a middle ear operation has to be doubted.

\section{Conclusions}

Biofilms play a major role in the development of cholesteatoma. In addition, biofilms on reimplanted ossicles maintain chronic infectious stimuli, which may finally contribute to recurrence of cholesteatoma [7]. According to current state of science, HHP fails to demonstrate reliable inactivation of colonizing microorganisms on ossicles by pressure conditions that have proved to be sufficient to inactivate cholesteatoma cells [23]. However, a reduction of colony forming units due to moderate HHP about several decadic logarithmic units for both planctonic bacteria and biofilms have been described for colonizers of the upper respiratory tract [23]. It remains unclear whether such a reduction of colony forming units may be sufficient in the per se nonsterile middle ear compartment to prevent severe infections or biofilm forming, other than in situations when sterile work is required like in bone and joint operations [51].

The inactivating effects of HHP may be facilitated by the presence of antimicrobial agents [23]. However, no composition of antibiotic drugs may cover the whole spectrum of potential resistance patterns, so surviving colonies cannot be excluded. Further studies on HHP combined with antibiotic drugs are desirable to identify optimal combinations in the future.

At present, it remains unclear whether ossicle tissue would tolerate relevant increases of pressure to levels that might allow for a more complete eradication of microbial agents. Moderate HHP treatment is suitable to reduce the number of microorganisms that colonize ossicles but fails to ensure a reliable sterilization.

\section{Conflict of Interests}

The authors declare that there is no conflict of interests as demanded by the guidelines of the International Committee of Medical Journal Editors.

\section{Acknowledgments}

This paper was funded by the Open Access Support Program of the Deutsche Forschungsgemeinschaft and the publication fund of the Georg August Universität Göttingen.

\section{References}

[1] J. Nevoux, M. Lenoir, G. Roger, F. Denoyelle, H. Ducou Le Pointe, and E.-N. Garabédian, "Childhood cholesteatoma," European Annals of Otorhinolaryngology, Head and Neck Diseases, vol. 127, no. 4, pp. 143-150, 2010.

[2] S. Khemani, A. Singh, R. K. Lingam, and A. Kalan, "Imaging of postoperative middle ear cholesteatoma," Clinical Radiology, vol. 66, no. 8, pp. 760-767, 2011.

[3] R. Charachon, S. Schmerber, and J. P. Lavieille, "Middle ear cholesteatoma surgery," Annales d'Oto-Laryngologie et de Chirurgie Cervico-Faciale, vol. 116, no. 6, pp. 322-340, 1999.

[4] K. Kazahaya and W. P. Potsic, "Congenital cholesteatoma," Current Opinion in Otolaryngology and Head and Neck Surgery, vol. 12, no. 5, pp. 398-403, 2004.

[5] R. Persaud, D. Hajioff, A. Trinidade et al., "Evidence-based review of aetiopathogenic theories of congenital and acquired cholesteatoma," The Journal of Laryngology \& Otology, vol. 121, no. 11, pp. 1013-1019, 2007.

[6] T. Yamamoto-Fukuda, H. Takahashi, and T. Koji, "Animal models of middle ear cholesteatoma," Journal of Biomedicine and Biotechnology, vol. 2011, Article ID 394241, 11 pages, 2011.

[7] H. Frickmann and A. E. Zautner, "Cholesteatoma-a potential consequence of chronic middle ear inflammation," Otolaryngology, vol. S5, article 001, 2012.

[8] A. E. Zautner, "Adenotonsillar disease," Recent Patents on Inflammation and Allergy Drug Discovery, vol. 6, no. 2, pp. 121129, 2012.

[9] I. Baumann, H. W. Diedrichs, P. K. Plinkert, and H. P. Zenner, "Autologous tissue in initial type I and type III tympanoplasty operations in chronic suppurative otitis media," Hno, vol. 45, pp. 990-996, 1997.

[10] G. Geyer and J. Rocker, "Results after rebuilding the ossicular chain using the autogenous incus, ionomer-cement- and titanium implants (tympanoplasty type III)," Laryngo-RhinoOtologie, vol. 81, no. 3, pp. 164-170, 2002. 
[11] J. C. Cheftel, "Review: high-pressure, microbial inactivation and food preservation [Revisión: alta-presión, inactivación microbiológica y conservación de alimentos]," Food Science and Technology International, vol. 1, no. 2-3, pp. 75-90, 1995.

[12] H. Alpas, N. Kalchayanand, F. Bozoglu, A. Sikes, C. P. Dunne, and B. Ray, "Variation in resistance to hydrostatic pressure among strains of food-borne pathogens," Applied and Environmental Microbiology, vol. 65, no. 9, pp. 4248-4251, 1999.

[13] P. Mentre and G. Hui Bon Hoa, "Effects of high hydrostatic pressures on living cells: a consequence of the properties of macromolecules and macromolecule-associated water," International Review of Cytology, vol. 201, pp. 1-84, 2000.

[14] P. Masson, C. Tonello, and C. Balny, "High-pressure biotechnology in medicine and pharmaceutical science," Journal of Biomedicine and Biotechnology, vol. 1, no. 2, pp. 85-88, 2001.

[15] I. Brook, "The role of anaerobic bacteria in otitis media: microbiology, pathogenesis, and implications on therapy," American Journal of Otolaryngology: Head and Neck Medicine and Surgery, vol. 8, no. 2, pp. 109-117, 1987.

[16] I. Brook, "Role of anaerobic bacteria in chronic otitis media and cholesteatoma," International Journal of Pediatric Otorhinolaryngology, vol. 31, no. 2-3, pp. 153-157, 1995.

[17] R. A. Chole and B. T. Faddis, "Evidence for microbial biofilms in cholesteatomas," Archives of Otolaryngology-Head and Neck Surgery, vol. 128, no. 10, pp. 1129-1133, 2002.

[18] S. K. Juhn, M.-K. Jung, M. D. Hoffman et al., "The role of inflammatory mediators in the pathogenesis of otitis media and sequelae," Clinical and Experimental Otorhinolaryngology, vol. 1, no. 3, pp. 117-138, 2008.

[19] J. C. Post, P. Stoodley, L. Hall-Stoodley, and G. D. Ehrlich, “The role of biofilms in otolaryngologic infections," Current Opinion in Otolaryngology \& Head and Neck Surgery, vol. 12, no. 3, pp. 185-190, 2004.

[20] J. C. Post, N. L. Hiller, L. Nistico, P. Stoodley, and G. D. Ehrlich, "The role of biofilms in otolaryngologic infections: update 2007," Current Opinion in Otolaryngology and Head and Neck Surgery, vol. 15, no. 5, pp. 347-351, 2007.

[21] E. Macassey and P. Dawes, "Biofilms and their role in otorhinolaryngological disease," The Journal of Laryngology and Otology, vol. 122, no. 12, pp. 1273-1278, 2008.

[22] F. Ricciardiello, M. Cavaliere, M. Mesolella, and M. Iengo, "Notes on the microbiology of cholesteatoma: clinical findings and treatment," Acta Otorhinolaryngologica Italica, vol. 29, no. 4, pp. 197-202, 2009.

[23] S. Dommerich, H. Frickmann, J. Ostwald et al., "Effects of high hydrostatic pressure on bacterial growth on human ossicles explanted from cholesteatoma patients," PLoS ONE, vol. 7, no. 1, Article ID e30150, 2012.

[24] B. Black, "Cholesteatomatous otitis media," Australian Family Physician, vol. 20, no. 6, pp. 806-812, 1991.

[25] D. Caprio, V. Strunski, B. Batteur et al., "Audiometric results of 81 ossiculoplasties after tympanoplasty with closed technique in chronic cholesteatomatous otitis," Annales d'Oto-Laryngologie et de Chirurgie Cervico Faciale, vol. 112, no. 3, pp. 107-117, 1995.

[26] V. Darrouzet, J. Dutkievicz, A. Chambrin, S. Diab, M. Dautheribes, and J. P. Bébéar, "Endocranial complications of cholesteatoma: apropos of 8 cases," Revue de Laryngologie Otologie Rhinologie, vol. 118, no. 2, pp. 79-86, 1997.

[27] T. Palva and H. Ramsay, "Chronic inflammatory ear disease and cholesteatoma: creation of auxiliary attic aeration pathways by microdissection," The American Journal of Otology, vol. 20, no. 2, pp. 145-151, 1999.
[28] T. Stark, A. Gurr, and H. Sudhoff, "Principles of cholesteatoma surgery," HNO, vol. 59, no. 4, pp. 393-400, 2011.

[29] T. Palva, "The pathogenesis and treatment of cholesteatoma," Acta Oto-Laryngologica, vol. 109, no. 5-6, pp. 323-330, 1990.

[30] C. Zini, S. Bacciu, E. Pasanisi, and G. Bortesi, "Pathogenesis and prevention of recurrent cholesteatoma following closed tympanoplasty," Acta Oto-Rhino-Laryngologica Belgica, vol. 45, no. 1, pp. 43-49, 1991.

[31] G. Roger, F. Denoyelle, P. Chauvin, N. Schlegel-Stuhl, and E.-N. Garabedian, "Predictive risk factors of residual cholesteatoma in children: a study of 256 cases," The American Journal of Otology, vol. 18, no. 5, pp. 550-558, 1997.

[32] H. Hildmann, B. Karger, and E. Steinbach, "Ear ossicle transplants for reconstruction of sound transmission in the middle ear. A histologic long-term study," Laryngo-Rhino-Otologie, vol. 71, no. 1, pp. 5-10, 1992.

[33] M. E. Glasscock III, C. G. Jackson, and G. W. Knox, "Can acquired immunodeficiency syndrome and Creutzfeldt-Jakob disease be transmitted via otologic homografts?" Archives of Otolaryngology - Head \& Neck Surgery, vol. 114, no. 11, pp. 12521255, 1988.

[34] P. Dost, "Animal tests and cell culture examinations on stapes reconstruction with diverse bio-materials," Laryngo-RhinoOtologie, vol. 79, no. 3, article 193, 2000.

[35] T. Zahnert and K.-B. Hüttenbrink, "Pitfalls in ossicular chain reconstruction," HNO, vol. 53, no. 1, pp. 89-103, 2005.

[36] M. Gross and R. Jaenicke, "Proteins under pressure. The influence of high hydrostatic pressure on structure, function and assembly of proteins and protein complexes," The FEBS Journal, vol. 221, no. 2, pp. 617-630, 1994.

[37] H. C. Crenshaw, J. A. Allen, V. Skeen, A. Harris, and E. D. Salmon, "Hydrostatic pressure has different effects on the assembly of tubulin, actin, myosin II, vinculin, talin, vimentin, and cytokeratin in mammalian tissue cells," Experimental Cell Research, vol. 227, no. 2, pp. 285-297, 1996.

[38] C. Balny, P. Masson, and K. Heremans, "High pressure effects on biological macromolecules: from structural changes to alteration of cellular processes," Biochimica et Biophysica Acta, vol. 1595, no. 1-2, pp. 3-10, 2002.

[39] P. Diehl, M. Schmitt, J. Schauwecker et al., "Effect of high hydrostatic pressure on biological properties of extracellular bone matrix proteins," International Journal of Molecular Medicine, vol. 16, no. 2, pp. 285-289, 2005.

[40] U. Magdolen, J. Auernheimer, C. Dahmen et al., "Growth promoting in vitro effect of synthetic cyclic RGD-peptides on human osteoblast-like cells attached to cancellous bone," International Journal of Molecular Medicine, vol. 17, no. 6, pp. 1017-1021, 2006.

[41] P. Diehl, E. Steinhauser, H. Gollwitzer et al., "Biomechanical and immunohistochemical analysis of high hydrostatic pressuretreated Achilles tendons," Journal of Orthopaedic Science, vol. 11, no. 4, pp. 380-385, 2006.

[42] E. Steinhauser, P. Diehl, M. Hadaller et al., "Biomechanical investigation of the effect of high hydrostatic pressure treatment on the mechanical properties of human bone," Journal of Biomedical Materials Research. Part B, Applied Biomaterials, vol. 76, no. 1, pp. 130-135, 2006.

[43] P. Diehl, M. Schmitt, G. Blümelhuber et al., "Induction of tumor cell death by high hydrostatic pressure as a novel supporting technique in orthopedic surgery," Oncology Reports, vol. 10, no. 6, pp. 1851-1855, 2003. 
[44] S. Dommerich, H.-W. Pau, T. Lindner, T. Just, and J. Ostwald, "Devitalization of cholesteatoma on human ossicles by hydrostatic high pressure treatment," Laryngo-Rhino-Otologie, vol. 89, no. 5, pp. 284-288, 2010.

[45] A. Vercammen, B. Vivijs, I. Lurquin, and C. W. Michiels, "Germination and inactivation of Bacillus coagulans and Alicyclobacillus acidoterrestris spores by high hydrostatic pressure treatment in buffer and tomato sauce," International Journal of Food Microbiology, vol. 152, no. 3, pp. 162-167, 2012.

[46] D. H. Kingsley, D. Guan, D. G. Hoover, and H. Chen, "Inactivation of hepatitis A virus by high-pressure processing: the role of temperature and pressure oscillation," Journal of Food Protection, vol. 69, no. 10, pp. 2454-2459, 2006.

[47] K. J. A. Hauben, D. H. Bartlett, C. C. F. Soontjens, K. Cornelis, E. Y. Wuytack, and C. W. Michiels, "Escherichia coli mutants resistant to inactivation by high hydrostatic pressure," Applied and Environmental Microbiology, vol. 63, no. 3, pp. 945-950, 1997.

[48] I. K. H. van Boeijen, R. O. Y. Moezelaar, T. Abee, and M. H. Zwietering, "Inactivation kinetics of three Listeria monocytogenes strains under high hydrostatic pressure," Journal of Food Protection, vol. 71, no. 10, pp. 2007-2013, 2008.

[49] G. Cebrián, C. W. Michiels, P. Manas, and S. Condón, "Biological approach to modeling of Staphylococcus aureus highhydrostatic-pressure inactivation kinetics," Applied and Environmental Microbiology, vol. 76, no. 21, pp. 6982-6990, 2010.

[50] R. F. Vogel and M. A. Ehrmann, "Effects of pressure on lactic acid bacteria," in High-Pressure Microbiology, C. Michiels, D. H. Bartlett, and A. Aertsen, Eds., pp. 117-144, American Society for Microbiology, 2008.

[51] H. Gollwitzer, W. Mittelmeier, M. Brendle et al., "High hydrostatic pressure for disinfection of bone grafts and biomaterials: an experimental study," The Open Orthopaedics Journal, vol. 3, pp. 1-7, 2009.

[52] I. K. H. Van Boeijen, A. A. E. Chavaroche, W. B. Valderrama, R. Moezelaar, M. H. Zwietering, and T. Abee, "Population diversity of Listeria monocytogenes LO28: phenotypic and genotypic characterization of variants resistant to high hydrostatic pressure," Applied and Environmental Microbiology, vol. 76, no. 7, pp. 2225-2233, 2010.

[53] S. Hörmann, C. Scheyhing, J. Behr, M. Pavlovic, M. Ehrmann, and R. F. Vogel, "Comparative proteome approach to characterize the high-pressure stress response of Lactobacillus sanfranciscensis DSM 20451T," Proteomics, vol. 6, no. 6, pp. 1878-1885, 2006.

[54] E. A. Eloe, F. M. Lauro, R. F. Vogel, and D. H. Bartlett, “The deepsea bacterium Photobacterium profundum SS9 utilizes separate flagellar systems for swimming and swarming under highpressure conditions," Applied and Environmental Microbiology, vol. 74, no. 20, pp. 6298-6305, 2008.

[55] M. Pavlovic, S. Hörmann, R. F. Vogel, and M. A. Ehrmann, "Transcriptional response reveals translation machinery as target for high pressure in Lactobacillus sanfranciscensis," Archives of Microbiology, vol. 184, no. 1, pp. 11-17, 2005.

[56] N. Igura, Y. Kamimura, M. S. Islam, M. Shimoda, and I. Hayakawa, "Effects of minerals on resistance of Bacillus subtilis spores to heat and hydrostatic pressure," Applied and Environmental Microbiology, vol. 69, no. 10, pp. 6307-6310, 2003.

[57] S. Koseki and K. Yamamoto, "pH and solute concentration of suspension media affect the outcome of high hydrostatic pressure treatment of Listeria monocytogenes," International Journal of Food Microbiology, vol. 111, no. 2, pp. 175-179, 2006.
[58] C. Bièche, M. Ritz, O. Tresse, M. Federighi, and M. De Lamballerie, "Impacts of treatment parameters on the inactivation of Campylobacter jejuni by high pressure: a statistical study of main effects and interactions," Letters in Applied Microbiology, vol. 48, no. 2, pp. 198-202, 2009.

[59] M. Brouillet, H. Gautier, A.-F. Miègeville, J.-M. Bouler, C. Merle, and J. Caillon, "Inactivation of Staphylococcus aureus in calcium phosphate biomaterials via isostatic compression," Journal of Biomedical Materials Research-Part B Applied Biomaterials, vol. 91, no. 1, pp. 348-353, 2009.

[60] A. Jofré, T. Aymerich, S. Bover-Cid, and M. Garriga, "Inactivation and recovery of Listeria monocytogenes, Salmonella enterica and Staphylococcus aureus after high hydrostatic pressure treatments up to $900 \mathrm{MPa}$," International Microbiology, vol. 13, no. 3, pp. 105-112, 2010.

[61] I. van Opstal, S. C. M. Vanmuysen, and C. W. Michiels, "High sucrose concentration protects $E$. coli against high pressure inactivation but not against high pressure sensitization to the lactoperoxidase system," International Journal of Food Microbiology, vol. 88, no. 1, pp. 1-9, 2003.

[62] J. Wen, R. C. Anantheswaran, and S. J. Knabel, "Changes in barotolerance, thermotolerance, and cellular morphology throughout the life cycle of Listeria monocytogenes," Applied and Environmental Microbiology, vol. 75, no. 6, pp. 1581-1588, 2009.

[63] N. Sagarzazu, G. Cebrián, S. Condón, B. Mackey, and P. Mañas, "High hydrostatic pressure resistance of Campylobacter jejuni after different sublethal stresses," Journal of Applied Microbiology, vol. 109, no. 1, pp. 146-155, 2010.

[64] P. Weber, P. Diehl, G. O. Hofmann et al., "Extracorporeal high hydrostatic pressure as a new technology for the disinfection of infected bone specimens," Biomedical Engineering, vol. 53, no. 4, pp. 190-198, 2008.

[65] R. R. S. Nelson, "Intrinsically vancomycin-resistant Grampositive organisms: clinical relevance and implications for infection control," The Journal of Hospital Infection, vol. 42, no. 4, pp. 275-282, 1999.

[66] L. Hall-Stoodley, F. Z. Hu, A. Gieseke et al., "Direct detection of bacterial biofilms on the middle-ear mucosa of children with chronic otitis media," Journal of the American Medical Association, vol. 296, no. 2, pp. 202-211, 2006.

[67] E. M. Jaryszak, E. M. Sampson, and P. J. Antonelli, "Biofilm formation by Pseudomonas aeruginosa on ossicular reconstruction prostheses," The American Journal of Otolaryngology-Head and Neck Medicine and Surgery, vol. 30, no. 6, pp. 367-370, 2009.

[68] E. M. Jaryszak, E. M. Sampson, and P. J. Antonelli, "Effect of ossicular prosthesis biofilms on middle ear scarring and hearing outcomes," Otology and Neurotology, vol. 30, no. 8, pp. 1191-1195, 2009. 


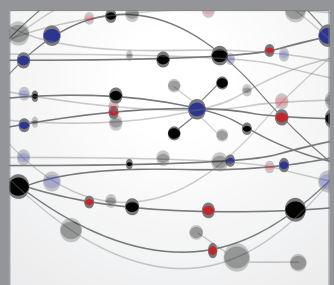

The Scientific World Journal
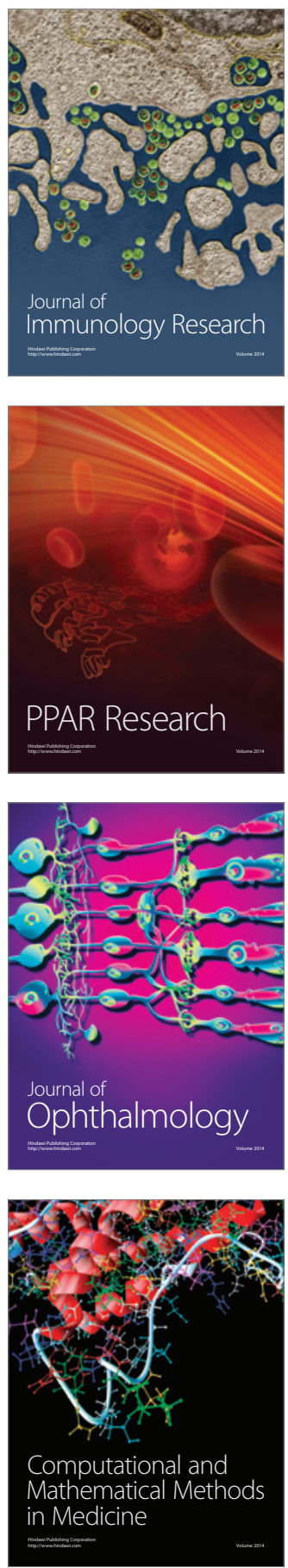

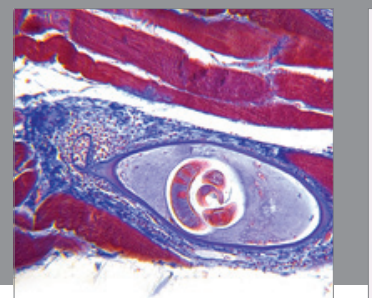

Gastroenterology

Research and Practice
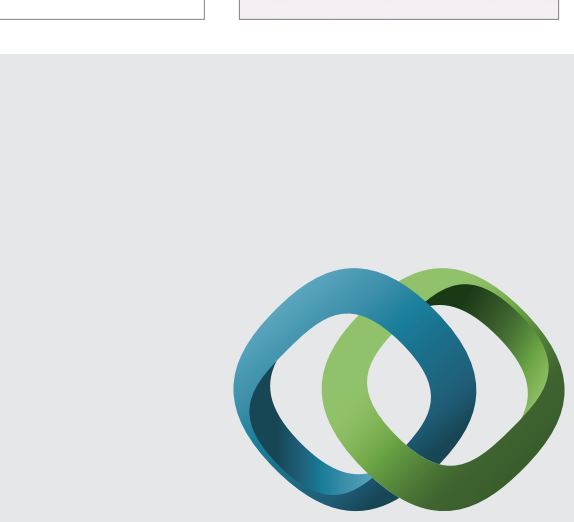

\section{Hindawi}

Submit your manuscripts at

http://www.hindawi.com
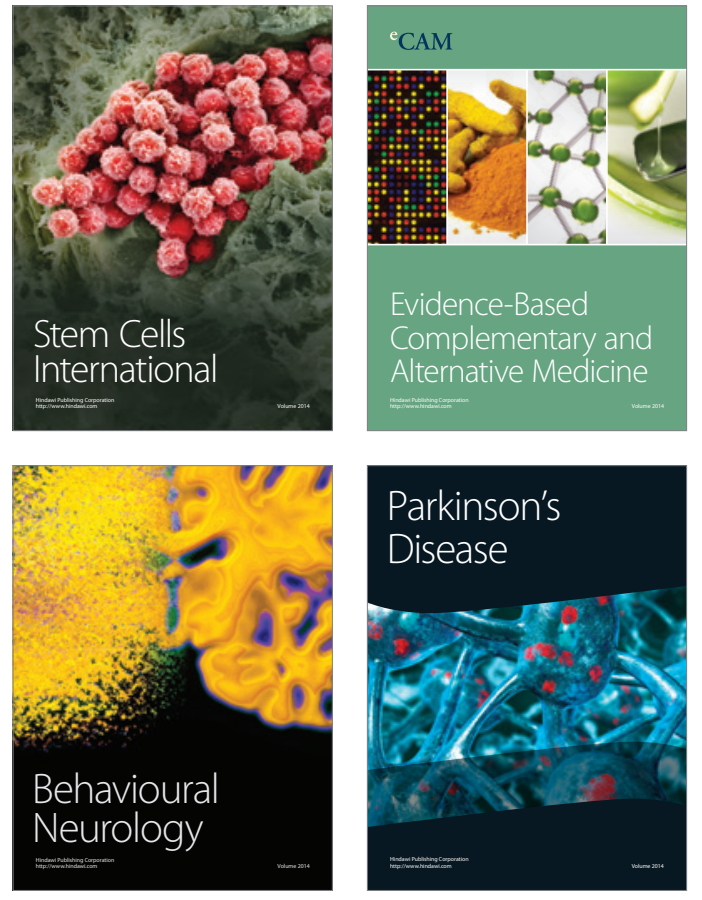
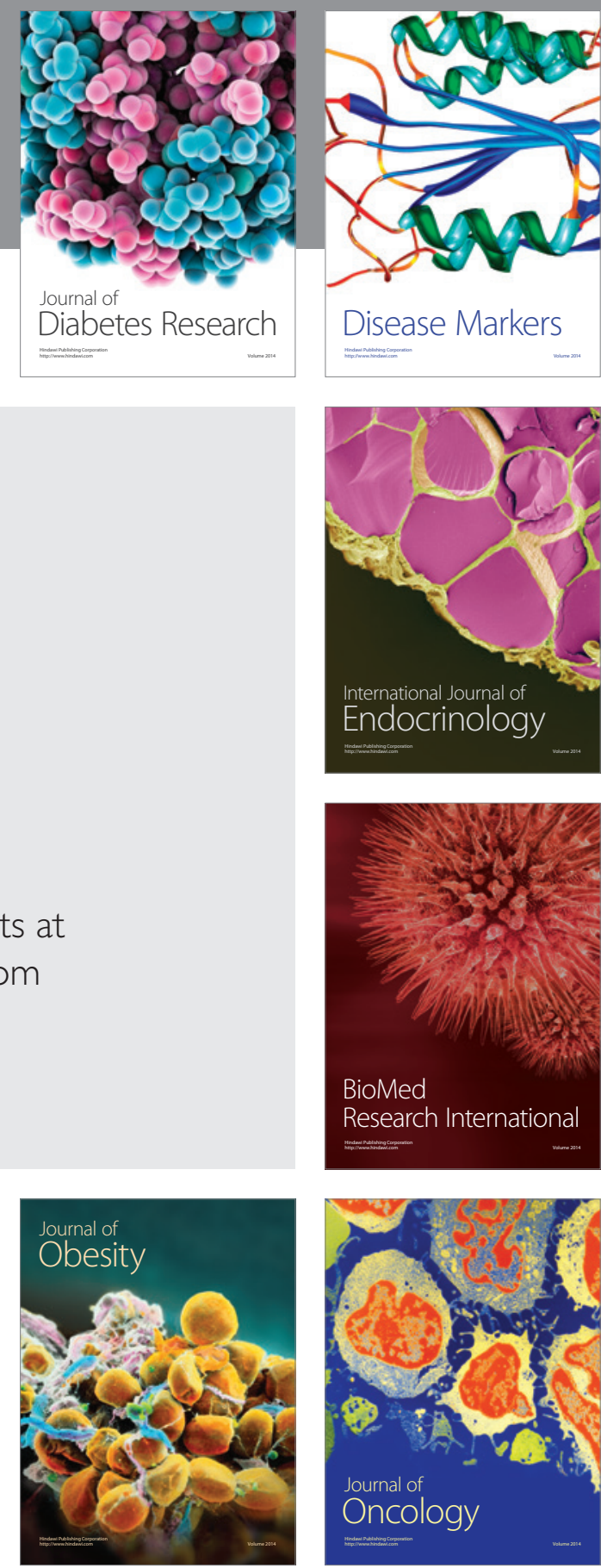

Disease Markers
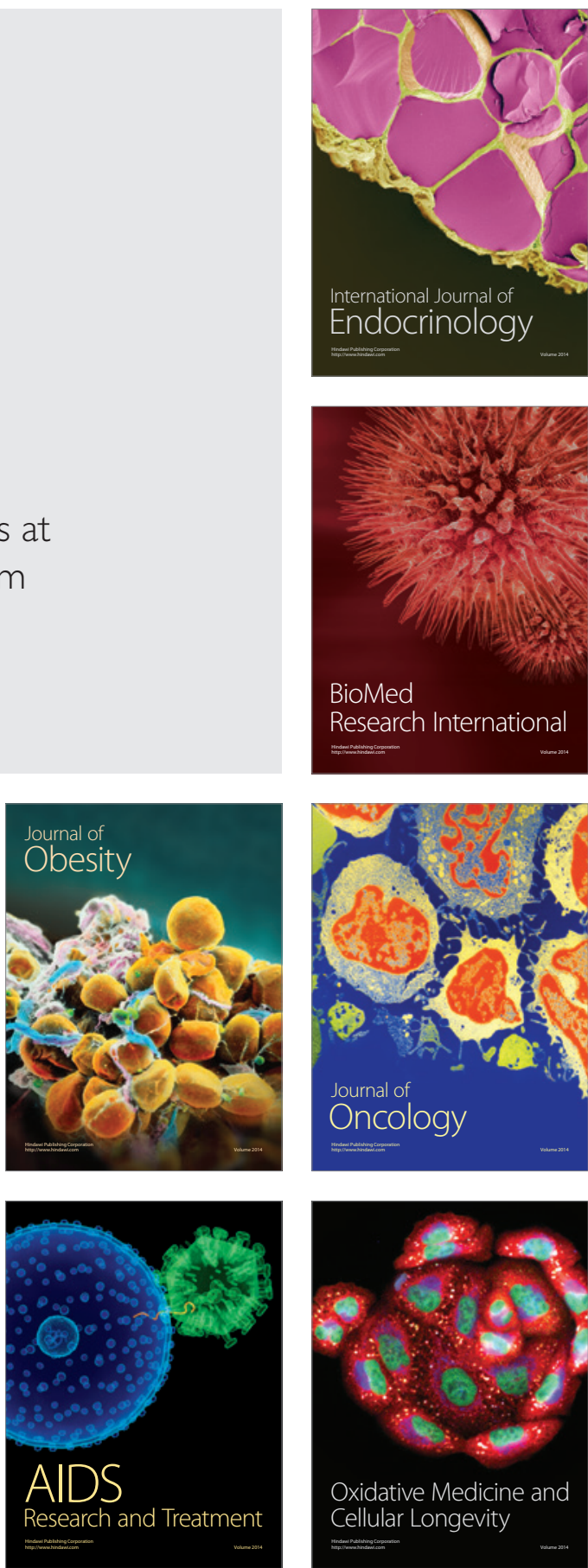